\title{
UMA ANÁLISE DA PROSÓDIA VISUAL IMAGÉTICA NA GRAPHIC NOVEL "LAÇOS"
}

\author{
An analysis of imagetic visual prosody at Graphic Novel "Laços"
}

\author{
Andressa Viana da SILVA \\ Instituto Federal de Rondônia \\ andressa.silva@ifro.edu.br \\ Natália Cristine PRADO \\ Universidade Federal de Rondônia \\ natalia.prado@unir.br
}

RESUMO: Esta pesquisa analisa a Prosódia Visual Imagética, isto é, a prosódia que pode ser percebida a partir das ilustrações que acompanham a linguagem verbal das Histórias em Quadrinhos (HQs). Assim, observamos as imagens de expressões faciais e gestos simultâneos à fala dos balões que funcionam como Marcadores Prosódicos Visuais Imagéticos (MPVI) na Graphic Novel "Laços", de autoria dos irmãos Vitor Caffaggi e Lu Caffaggi. Com este estudo, foi possível perceber também que os Marcadores Prosódicos Lexicais (MPL) tradicionalmente presentes em outros gêneros escritos narrativos, como romances (CAGLIARI, 2002), não aparecem nesta HQ. Nossa hipótese é a de que isso ocorre, pois, diferentemente das narrativas clássicas, em uma novela gráfica, as imagens participam da narração da história, de modo que elas podem ser construídas sem a presença de um narrador, o que resulta em outras manifestações prosódicas características do hipergênero HQs, como os MPVI. Esperamos, com este estudo, contribuir para a reflexão sobre as diferentes manifestações da prosódia em HQs. PALAVRAS-CHAVES: Prosódia Visual; Histórias Em Quadrinhos; Marcadores Prosódicos Visuais Imagéticos.

\begin{abstract}
This research analyzes the Visual Imagetic Prosody, that is, the prosody that can be perceived from the illustrations that accompany the verbal language of the comics. Thus, we observed the images of facial expressions and simultaneous gestures to the speech of the balloons that function as Prosodic Visual Imagetic Markers (PVIM) in the Graphic Novel "Laços", by the brothers Vitor Caffaggi and Lu Caffaggi. Through this study, we could notice that the Lexical Prosodic Markers (LPM) traditionally present in other narrative written genres, such as novels (CAGLIARI, 2002), do not appear in this comic. Our hypothesis is that this occurs because, unlike traditional narratives, in a graphic novel, the images participate in the narration
\end{abstract}


of the story, so that they can be constructed without the presence of a narrator, which results in other prosodic manifestations typical of the hypergender comics, like PVIM. We hope, with this study, to contribute to the reflection on the different manifestations of prosody in comics. KEYWORDS: Visual Prosody; Comics; Prosodic Visual Imagetic Markers.

\section{INTRODUÇÃO}

As Histórias em Quadrinhos (HQs) têm se apresentado como um objeto de estudo para o campo da Linguística já há alguns anos. Ramos (2006) observa que muito do atual interesse em se estudar HQs pode estar relacionado à sua presença em exames de vestibulares e à sua inclusão nas práticas pedagógicas propostas pelos Parâmetros Curriculares Nacionais (PCN).

Todavia, embora o interesse em torno dos quadrinhos tenha aumentado, ainda são poucos os trabalhos que se dedicam a observar as linguagens dos quadrinhos em sua relação com a fonética e a fonologia da língua portuguesa. Desse modo, podemos dizer que, mesmo hoje, são poucos os estudos que realizam análises fonéticas e fonológicas, a partir das HQs ${ }^{1}$.

Brandão (2017, p. 36) explica que as HQs são uma composição de imagem (não necessariamente desenhada) e texto (não necessariamente verbal). Portanto, as HQs podem ser consideradas uma mídia interativa híbrida, que desenvolve as aptidões interpretativas verbais e não-verbais dos leitores. Ramos (2007, p. 1580) acrescenta que

nos balões, em geral em discurso direto, teríamos representados os turnos conversacionais, as pausas, hesitações, truncamentos, sobreposição de vozes. O código visual se encarregaria de indicar os aspectos extra-verbais ou paralingüísticos da conversação, como as expressões faciais ou um movimento do corpo. O formato das letras e o contorno dos balões indicariam tom de voz mais elevado, mais baixo, a emoção sentida no momento da fala do personagem.

Dentre os estudos que se dedicam a analisar especificamente linguagem verbal dos quadrinhos, há trabalhos (como EGUTI, 2001; PASSARELI, 2004 e RAMOS, 2005) que

\footnotetext{
${ }^{1}$ Considerando esta lacuna, Prado propôs o projeto de pesquisa "A língua dos balões: um estudo fonético/fonológico e ortográfico do Português Brasileiro representado nos quadrinhos nacionais", que foi desenvolvido como pesquisa de pós-doutorado júnior com apoio do CNPq entre os anos de 2016 e 2017 (processo 150124/2016-3).
} 
ressaltam os aspectos da oralidade ali representada. Segundo essas pesquisas, podemos notar que os diversos tipos de quadrinhos são um terreno fértil para a representação da língua falada. Entretanto, é importante considerar que os quadrinhos têm como particularidade a união de texto e imagem, assim, as HQs têm como característica a forte presença da linguagem não verbal.

Segundo Pacheco (2006, p. 206), a língua escrita pode ser vista como uma tentativa de representação gráfica da língua falada. A autora considera que o sistema de escrita possui vários recursos para resgatar as sutilezas e nuances típicas da oralidade, como os sinais de pontuação, por exemplo. A análise de marcadores prosódicos na escrita já vem sendo tradicionalmente realizada por alguns estudiosos, como Cagliari (1989). Para o autor, podemos encontrar "muitas marcas prosódicas nos textos, sobretudo, em narrativas"(CAGLIARI, 2002, p. 1).

Considerando a característica híbrida das HQs, o desafio dessa pesquisa se encontra em analisar os recursos prosódicos presentes na linguagem não verbal, isto é, nas imagens deste hipergênero. Para Pacheco (2011, p. 96), é possível

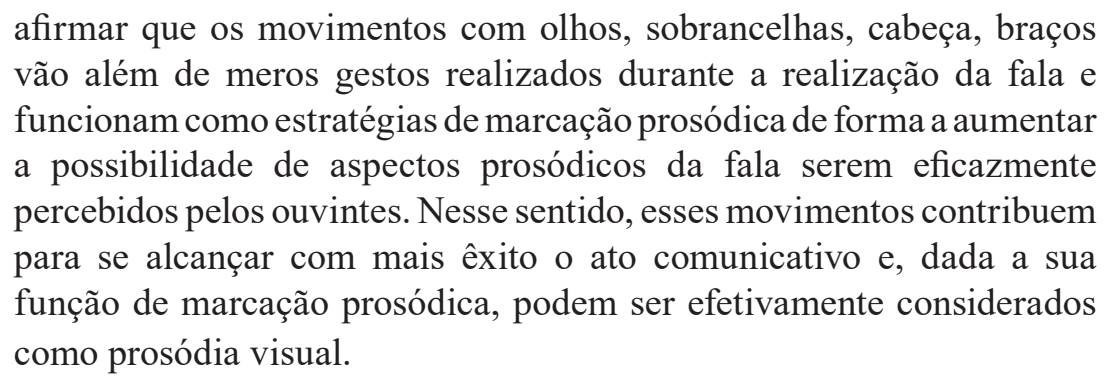

Assim se instaura a inquietação deste estudo, pois as HQs são ricas em marcas visuais que guiam a leitura dos quadrinhos, evidenciam emoções e carregam possibilidades de significações. Dessa forma, pretendemos analisar a Prosódia Visual Imagética, isto é, a prosódia que pode ser percebida a partir das ilustrações que correspondem aos aspectos paralinguísticos dos quadrinhos. Assim, observaremos as imagens de expressões faciais e gestos simultâneos a fala dos balões enquanto Marcadores Prosódicos Visuais Imagéticos (MPVI) na Graphic Novel (GN) "Laços", de autoria dos irmãos Vitor Caffaggi e Lu Caffaggi ${ }^{2}$.

Observamos, neste estudo, que os Marcadores Prosódicos Lexicais (MPL)

\footnotetext{
${ }^{2}$ Este estudo é um aprofundamento da pesquisa de mestrado intitulada "Os marcadores prosódicos na história em quadrinhos Laços" (SILVA, 2019), desenvolvida no Mestrado Acadêmico em Letras da Fundação Universidade Federal de Rondônia (UNIR).
} 
tradicionalmente presentes em outros gêneros narrativos, como romances (CAGLIARI, 2002) não se apresentam nesta HQ. Acreditamos que isso ocorre pois, diferentemente das narrativas tradicionais, em uma novela gráfica as imagens participam da narração da história de modo que as GN podem ser construídas sem a presença de um narrador.

A fim de organizar a discussão da temática apresentada neste capítulo, iniciaremos abordando o hipergênero HQs, já apresentando nosso objeto de pesquisa. Em seguida, apresentamos algumas reflexões sobre prosódia, marcadores prosódicos na escrita e prosódia visual. Por fim, apresentaremos nossas análises dos MPVI em "Laços". Esperamos, com esse estudo, contribuir para as reflexões sobre os recursos utilizados para representar a prosódia em HQs.

\title{
A HISTÓRIA EM QUADRINHOS "LAÇOS"
}

A imagem pode ser considerada, de acordo com Vergueiro (2015), o elemento básico das HQs, o que, possivelmente, contribui para sua popularização, sobretudo entre crianças e jovens. Entretanto, justamente por serem consideradas um meio de comunicação de massa popular, durante muito tempo, os quadrinhos foram vistos pelo senso como comum como uma leitura menos importante, um mero passatempo. Para Vergueiro (2015, p. 8)

\begin{abstract}
por representarem um meio de comunicação de vasto consumo e com conteúdo, até os dias de hoje, majoritariamente direcionado às crianças e jovens, as HQs cedo se tornaram objeto de restrição, condenadas por muitos pais e professores do mundo inteiro. De uma maneira geral, os adultos tinham dificuldade para acreditar que, por possuírem objetivos essencialmente comerciais, os quadrinhos pudessem também contribuir para o aprimoramento cultural e moral de seus jovens leitores.
\end{abstract}

A linguagem visual icônica das HQs, que pode ou não vir associada à linguagem verbal, se apresenta como uma sequência de quadrinhos (ou vinhetas) organizada no sentido da leitura do texto escrito $^{3}$ e, tradicionalmente, apresenta uma narrativa ficcional ou real.

\footnotetext{
${ }^{3}$ Dessa forma, nas HQs ocidentais, essa ordem se dá do alto para baixo e da esquerda para a direita. Vergueiro (2015, p. 33) explica que nos países asiáticos, essa representação ocorre da direita para a esquerda, acompanhando a leitura das escritas japonesa e chinesa, por exemplo. Essa ordem é mantida mesmo quando os mangás (tradicionais quadrinhos japoneses) são traduzidos e publicados em países ocidentais, como o Brasil.
} 
Vergueiro (2015, p. 33) lembra que a técnica de desenho utilizada nos quadrinhos vai depender do objetivo de cada criador. Por exemplo, há artistas que desenham tudo a lápis e outros que utilizam programas gráficos na hora de criar. Conforme afirma Zimbres (2017, p. 28), o "desenho é o que você quiser fazer dele e a qualidade não está na perfeição da cópia da realidade”. Brandão (2017, p. 38) afirma que nem todas as HQs são produzidas com desenhos (embora a maioria seja). Assim, as HQs podem ser produzidas com fotografias, pinturas, recortes, colagens, assemblagens ${ }^{4}$ e outros recursos.

Ramos (2007) constatou que há elementos comuns em diferentes HQs, entre os quais podemos destacar dois que predominam: a sequência narrativa, apresentada em um ou mais quadros; e o uso da linguagem gráfica, por exemplo, os balões. O autor explica que "esses elementos antecipam informações genéricas ao leitor e ajudam no processo de identificação e de leitura dos diferentes gêneros que compartilham tais características" (RAMOS, 2009, p. 352).

Considerando tais reflexões, para alguns autores, como Cagnin (1975), Mendonça (2002) e o próprio Ramos (2007, 2009, 2012, 2017), as HQs devem ser classificadas como um hipergênero, e não, simplesmente, um gênero textual. Isso significa entender que o termo "quadrinhos" é um rótulo que agrega diferentes gêneros, cada um com suas características, funcionando como "um guarda-chuva para diferentes gêneros, todos autônomos, mas com características afins" (RAMOS, 2009, p. 366).

Podemos entender melhor o que é hipergênero nas seguintes palavras de Maingueneau (2006, p.244):

no caso dos rótulos que se referem a um tipo de organização textual, mencionamos em primeiro lugar aquilo a que demos o nome de hipergênero. Trata-se de categorizações como 'diálogo', 'carta', 'ensaio', 'diário' etc. que permitem 'formatar' o texto. Não se trata, diferentemente do gênero do discurso, de um dispositivo de comunicação historicamente definido, mas um modo de organização com fracas coerções que encontramos nos mais diversos lugares e épocas e no âmbito do qual podem desenvolver-se as mais variadas encenações da fala. O diálogo, que no Ocidente tem estruturado uma multiplicidade de textos longos ao longo de uns 2.500 anos, é um bom exemplo de hipergênero. Basta fazer com que conversem ao menos dois locutores para se poder falar de "diálogo". O fato de o diálogo - assim como a correspondência epistolar - ter sido usado de modo

\footnotetext{
${ }^{4}$ A palavra "assemblagem" é usada para definir colagens com objetos e materiais tridimensionais, um termo francês posto à arte por Jean Dubuffet, em 1953.
} 
tão constante, decorre do fato de que, por sua proximidade com o intercâmbio conversacional, ele permite formatar os mais diferentes conteúdos.

A GN é um formato de HQ que vem adquirindo grande popularidade entre o público leitor. "Um contrato de Deus", de Will Eisner (1940), obra que apresentou inovações na escrita e no desenho, é considerada a primeira representante deste gênero. Trata-se de uma publicação que reuniu quatro histórias curtas que se passam no período da recessão econômica que atingiu os Estados Unidos da América na década de 1930. Com essa publicação, o quadrinista tinha a intenção de provar que as HQs não são leituras destinadas apenas para o público infantil (SANTOS, 2018).

Esse formato de HQ se caracteriza por ter capa dura ou brochura, o que lembra a estrutura convencional de um livro. É possível observar nas GNs considerável liberdade artística: os desenhos, os roteiros e a própria disposição dos quadrinhos são inovadores, fugindo de temas habituais de histórias quadrinizadas. Uma configuração sofisticada que abriu as portas das livrarias para os quadrinhos, um material diferente por sua literalidade marcante. De acordo com Santos (2018), instituiu-se, assim, um novo mercado, que atingia um público mais exigente e que conquistava os que não costumavam ler os formatos mais populares de narrativas sequenciais.

A GN é uma obra autoral ${ }^{5}$, destinada, principalmente, ao público adulto e, por esse motivo, aborda temas com mais densidade e profundidade. Traz assuntos atuais, como temas políticos, e ainda de cunho existencial. Ela abrange ainda os relatos biográficos, jornalísticos e autobiográficos, tal qual narrativas de ficção tradicionais, com protagonistas conhecidos de super-heróis.

No Brasil, ainda são poucas as publicações neste formato, apesar de ser crescente o número de iniciativas dessa natureza, como é o caso do projeto Graphic Maurício de Sousa Produções - Graphic MSP, que consiste em recriações dos conhecidos personagens da Turma da Mônica clássica feitas por outros artistas brasileiros, consagrados e com estilos diversos, diferentes do padrão das revistas mensais tradicionais de Maurício de Sousa.

A Turma da Mônica é um dos coletivos de personagens infantis mais importantes

\footnotetext{
${ }^{5}$ Obra autoral é aquela em que, geralmente, o seu criador produz o roteiro, faz os desenhos, como também a finalização da arte, e, às vezes, até a colorização da história (SANTOS, 2018). Nos formatos mais populares, como os tradicionais gibis da Turma da Mônica, normalmente há um processo de produção em escala industrial em que vários profissionais trabalham em conjunto (roteiristas, letristas, coloristas etc.).
} 
nacionalmente, junto com a turma do Sítio do Pica-Pau Amarelo, de Monteiro Lobato. São histórias reconhecidas e que possuem grande circulação no país. A marca Mauricio de Sousa, atualmente, responde por 2.500 produtos de mais de 150 empresas.

Em 2009, Mauricio de Sousa lançou o álbum MPS 50, no qual 50 artistas brasileiros publicaram releituras de suas obras consagradas. Vitor Caffaggi foi o escolhido para recriar os principais personagens (Mônica; Cebolinha; Cascão e Magali) da carreira de Sousa. A partir daí, Vitor e sua irmã, Lu Caffaggi, foram convidados a elaborarem uma releitura dos personagens da Turma da Mônica em formato GN. Assim, "Laços"(a segunda da série Graphic MSP) foi escrita e desenhada pelos irmãos Caffaggi, em 2013. $\mathrm{O}$ enredo debate opoder da amizade e se desenvolve em torno da busca por Floquinho, cachorro de Cebolinha, que desaparece misteriosamente. O trabalho de recriação trouxe à história uma renovação técnica, com efeitos particulares.

O sucesso foi tamanho que ganhou quatro prêmios no HQMix (uma das maiores premiações dos quadrinhos nacionais), como também ganhou duas sequências: Lições (2015) e Lembranças (2017), produzidas pelos mesmos autores. Além disso, alcançou a arte cinematográfica, com o lançamento do filme em junho de 2019.

\section{OS MARCADORES PROSÓDICOS NA ESCRITA}

Segundo Cagliari (1989), um sistema de escrita como o nosso tem recursos que manifestam ao leitor as nuances e sutilezas da fala e isso é muito evidente dentro de uma leitura adequada, principalmente em voz alta. De acordo com o autor, em um texto escrito, principalmente em narrativas, há marcas gráficas que têm como função primordial indicar ao leitor como deverão ser lidas as variações melódicas e entoacionais do texto. Dessa maneira, as marcas prosódicas podem variar desde o uso da pontuação até a formatação textual. Esses MP, segundo Pacheco (2006), podem se dividir em dois tipos, no geral: os Marcadores Prosódicos Gráficos - MPG - e os Marcadores Prosódicos Lexicais - MPL.

Os MPG, de acordo com Pacheco (2007), são todos os sinais de pontuação: a vírgula, o ponto final, a exclamação. Por meio das sinalizações gráficas de pontuação, indica-se o modo de fala que pode ser acessado pela escrita ou de forma auditiva, apesar de serem apresentados sob a forma visual. É interessante ressaltar ainda que "a presença de um sinal de pontuação incita variações melódicas no enunciado que está sob o seu escopo" (PACHECO, 2007, p. 203).

Conforme Catach (1998), os sinais de pontuação agregam, atualmente, uma multiplicidade de funções, contudo, Cagliari (1995) acrescenta que esses MPG vêm 
desde os registros primitivos, já nos primeiros documentos escritos pelos sumérios. Sendo assim, "a primeira manifestação da escrita veio não só com os caracteres, mas também com marcas discursivas que hoje costumamos chamar de sinais de pontuação" (CALGIARI, 1995, p. 178).

Silva (2019) defende que características como cor, tamanho e textura das letras, bem como o balão de fala ${ }^{6}$ das HQ são elementos que podem ser classificados como MPG. O balão, por exemplo, consiste em convenção gráfica que segundo, são como "recipientes simbólicos ou contendedores das locuções dos personagens falantes" e podem necessitar de elementos verbais escritos para completar a significação, porém isso só confirma que são MPG da escrita, afinal, acompanham a linguagem verbal, dando indícios para a forma como se deve ler. A estrutura é delimitada por linhas que contornam o formato constituinte do balão. Esse contorno pode variar muito e é essa peculiaridade que o torna um MPG.

Por sua vez, as palavras que fazem referências ao modo de falar são MPL, pois guiam o leitor a determinada leitura, como exemplo temos a palavra "gritar", bem como "sussurrar", e as expressões "falar rapidamente", ou "em tom alto". Sendo assim, por meio da entonação é possível medir atitudes do falante, tais como a arrogância e polidez, entre outras.

As variações melódicas presentes no contexto comunicativo, decorrentes da atitude do falante, da emoção, também são prosódicas. Como afirma Cagliari (2002, p. 7), elas "caracterizam atitudes do falante, emoções e modos de dizer que fazem uma referência à prosódia da língua, uma vez que tais atitudes, emoções e modos de dizer precisam ser realizados foneticamente de uma determinada maneira e não de outra". De acordo com o estudioso, esses aspectos de situações comunicativas são apresentados na escrita por meio de expressões semânticas, podendo pertencer a uma classe gramatical, pois são entradas no léxico mental dos falantes. Essas referências semântico-lexicais têm um cunho prosódico e conseguem pertencer a diferentes categorias gramaticais, tais como um advérbio ou adjetivo (CAGLIARI, 2002). Portanto, da mesma forma que uma frase pode ter seu sentido mudado em função do MPG que vem acarretado, a mesma coisa pode ocorrer com a frase que o MPL acompanha.

Vejamos no exemplo a seguir, extraído de Pacheco (2006, p. 111).

\footnotetext{
${ }^{6}$ É relevante lembrar que os balões costumam ter um apêndice que se alonga para fora, com a intenção de indicar o falante. Esse apêndice normalmente é apontado para a cabeça ou boca da personagem e pode ser chamado de rabicho (SANTOS, 2015).
} 
(...) uma frase como 'ela disse que ia embora' pode expressar estados e espíritos diferentes de quem a pronuncia, a depender do marcador prosódico lexical que a acompanha:

a) Ela disse calmamente que ia embora.

b) Ela disse gritando que ia embora.

c) Ela disse lentamente que ia embora.

d) Ela disse desesperada que ia embora.

f) Ela disse sussurrando que ia embora.

g) Ela disse aos berros que ia embora.

A pronúncia de fala das opções citadas no exemplo anterior vai depender do MPL que a acompanha, ou seja, cada uma das palavras grifadas nas frases remete a um comportamento prosódico específico, que provoca atitudes como o aumento ou a baixa do tom e o volume da voz. Em cada uma das situações ficam expressas emoções e colocações diversas para a leitura. Pacheco (2016, p. 111) acrescenta que:

\begin{abstract}
é fácil verificar os efeitos de sentido que a alteração da palavra que segue o verbo disse acarreta a frase aqui analisada. Cada uma das palavras apresentadas remete a um comportamento prosódico específico, que implica em aumentar ou abaixar o tom e o volume da voz. Acelerar ou reduzir a velocidade de fala. Em cada uma dessas situações, estão expressas atitudes e emoções diversas do falante.
\end{abstract}

Vimos, até aqui, que a escrita possui diferentes recursos para representar variações prosódicas, variando de acordo com a intenção por parte de quem emite o texto. O uso desses recursos é diverso e pode ser usada em diferentes gêneros de textos para indicar ao leitor o comportamento prosódico almejado por quem escreve.

\title{
A PROSÓDIA VISUAL
}

Ekman e Friesen (1978) analisaram as expressões de certas emoções e, assim, desenvolveram o Facial Action Coding Systems (FACS), uma espécie de roteiro que guia as análises dos movimentos da face e suas significações. Na análise, os autores defendem que quatro emoções (alegria; tristeza; raiva e medo) vão ao encontro de aspectos visuais ligados à expressão de alegria, quando são relacionados à expressão de tristeza, como também mostram que os gestos de sobrancelha, da bochecha, do lábio e outros são relevantes para a comunicação.

A multifuncionalidade de movimentos que caracterizam os gestos, revela emoções 
e demonstrações de possíveis significados que se estruturam na face. Ekman e Friensen (1969) acrescentam que esses movimentos também são utilizados como "ilustradores", por acompanharem a fala (com funções diversas). Ekman (1999) ressalta ainda que certas emoções são mais evidentes quando levamos em consideração a expressão facial, por exemplo, a raiva e o medo, são facilmente reconhecidas pelo julgamento dos movimentos faciais.

Por meio dessas observações e pesquisas, podemos perceber que as emoções e as expressões que refletem nos gestos visuais são involuntárias, e que, a cada dia, eles veem sendo refinadas e evoluindo junto com a espécie humana, com o intuito de comunicar sempre mais e melhor (EKMAN, 1992). Com a ilustração não poderia ser diferente, da mesma forma que o processo de comunicação por gestos visuais sofra variação e mudanças, também ocorrem modificações nas técnicas de representação gráfica imagética desses gestos.

No texto construído com imagens, em que há forte presença da linguagem não verbal, como é o caso dos quadrinhos, por isso, também encontramos aspectos visuais que influenciam a caracterização de certas emoções e podem condicionar comportamentos de leitura.Para entender melhor o assunto, precisamos primeiro considerar que os recursos gráficos imagéticos que representam personagens e afins na HQ analisada são inspirados em uma realidade visual, como também é importante lembrar que a interpretação de um texto visual pode interferir no significado do que se comunica na linguagem verbal.

Entretanto, a problemática central desta pesquisa se instaura quando as ilustrações encontradas nos textos não se enquadram como MPG, nem como MPL, logo, os aspectos da linguagem não verbal, fundamentais para a leitura de HQs como "Laços", acabam não sendo analisados enquanto marcas prosódicas, mesmo sendo importantes para a representação da prosódia em narrativas gráficas.

Hodiernamente, já se ouve falar, de forma singela, em prosódia visual, todavia ainda de maneira tímida, portanto, há muito que se estudar sobre a prosódia não verbal de HQs. Pacheco (2016, p. 1) define prosódia visual da seguinte maneira:

durante uma conversa, os falantes frequentemente movimentam o corpo e fazem gestos faciais. Muitas das expressões faciais e deslocamentos da cabeça estão atrelados à estrutura prosódica. Nesses casos, esses movimentos funcionam como uma prosódia visual. Assim, por exemplo, um acento lexical é frequentemente acompanhado por um movimento de cabeça. Uma elevação da voz no fim de uma frase pode acontecer com a elevação da cabeça, possivelmente combinado com a elevação das sobrancelhas. Nesse sentido, esses movimentos faciais e 
corporais não são meros movimentos realizados ao caso pelo falante, mas, pelo contrário, eles carregam consigo uma informação linguística, em particular, de cunho prosódico.

Assim, é importante pontuar que, para uma análise mais completa da prosódia das HQs, torna-se fundamental observar o que está sendo dito na linguagem verbal do quadrinho, mas, conjuntamente, observar as ilustrações, que podem ou não vir acompanhadas do texto verbal. Afinal, a sobrancelha arqueada no rosto da personagem que está desenhada pode ser um detalhe fundamental para definir o comportamento prosódico do leitor no momento leitura da narrativa quadrinizada.

Sabendo das pesquisas atuais, tais como Pacheco (2011), indicam que os sinais de cabeça contribuem para a segmentação do contínuo da fala, desempenhando um papel importante no processamento audiovisual da fala, consideramos que a Prosódia Visual Imagética é importante para a leitura e a interpretação de textos que contenham ilustrações, como é o caso das GN.

\section{ANÁLISE DOS MARCADORES PROSÓDICOS IMAGÉTICOS EM "LAÇOS"}

A obra analisada, "Laços", não contém palavras e expressões que fazem referência ao modo de falar, ou seja, os MPL. Contudo, como demonstraremos em nossas análises, encontramos marcas prosódicas visuais exercendo uma função similar aos MPL.

$\mathrm{O}$ fato de ser uma narrativa quadrinizada influenciou este resultado, porque vemos que esse tipo de escrita costuma utilizar falas diretas, direcionadas por balões, logo, não há necessidade de um verbo dicendi, por exemplo, ou de uma colocação descritiva específica, como "fulano gritou", afinal, o desenho do balão, o estilo de letra e as imagens da HQ podem indicar que determinada personagem disse algo "gritando". Assim, o leitor poderá entender que a leitura deve ser diferenciada sem, necessariamente, virem escritas as coordenadas, como ocorre no gênero romance, em que o narrador anuncia quem vai dizer e como vai dizer.

De acordo com Cagliari (2002), esse aspecto de situação comunicativa que apresenta uma expressão semântica (evidenciando um comportamento/atitude) que pertence a uma classe gramatical, é um modo de entrada para o léxico mental dos falantes. Desse modo, é essencial destacar que, além do MPL presente, a linguagem não verbal também é um fator importante para a leitura do comportamento prosódico da fala das personagens. À vista disso, não há como desconsiderar a leitura visual nos quadrinhos. 
Dessa maneira, é clara a importância da imagem para a leitura da narrativa. As linguagens verbal e não verbal misturam-se em uma amálgama para possibilitar a significação. Em "Laços",os desenhos podem ser considerados MPVI por apresentar incitações de atitudes, emoções e modos de dizer que apontam para o caminho de uma determinada interpretação prosódica do texto verbal. Vejamos alguns exemplos nas imagens a seguir:

\section{Imagem 1:}

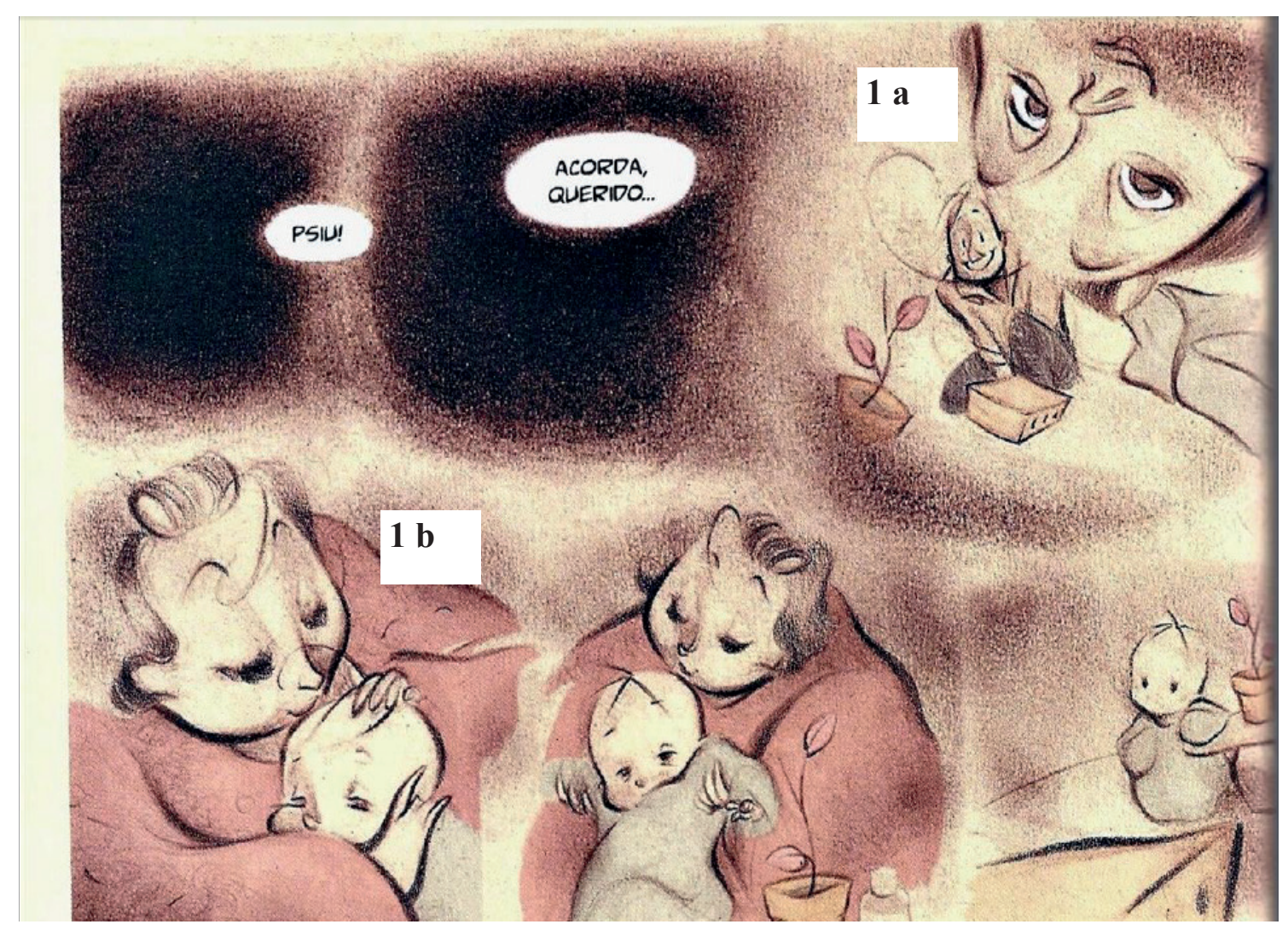

Fonte: Revista “Laços”(CAFAGGI, V.; CAFAGGI, L., p. 8), 2013.

Nesta imagem, observamos a linguagem verbal sendo introduzida por um balão sem apêndice em tamanho pequeno e com letras também pequenas, o que pode indicar uma fala suave. Acima (em 1.a), muda-se a perspectiva do desenho, ressaltando-se uma das características dessa obra, que é a variedade de pontos de vista. Essas posições são diferenciadas para que o leitor tenha múltiplas possibilidades de enxergar a narrativa.

As cenas posteriores da imagem 1 (em 1.b) contêm desenhos que sugerem que 
a mãe sussurra no ouvido do filho para acordá-lo. Isso é possível de se interpretar por conta da "ternura" e "delicadeza" colocadas nos traços da personagem que representam sua expressão facial. Além disso, o desenho do bebê que dormia não demonstra que ele acorda assustado; pelo contrário, seu semblante é de preguiça, lentidão, alguém que foi sutilmente acordado. Assim, os elementos verbais, o tamanho do balão e as imagens trabalham em conjunto para indicar o comportamento de leitura da fala da mãe. $\mathrm{O}$ verbo sussurrar não esteve expresso na escrita graficamente, portanto o MPL não aparece, mas a imagem o denota, por todas as evidências citadas, também pela proximidade da boca da mãe ao ouvido do bebê (em 1.b). Assim, podemos dizer que as imagens contribuem para a leitura sussurrada do texto, mesmo não existindo um "narrador" que indica ao leitor "a mãe disse sussurrando: acorda, querido!". 


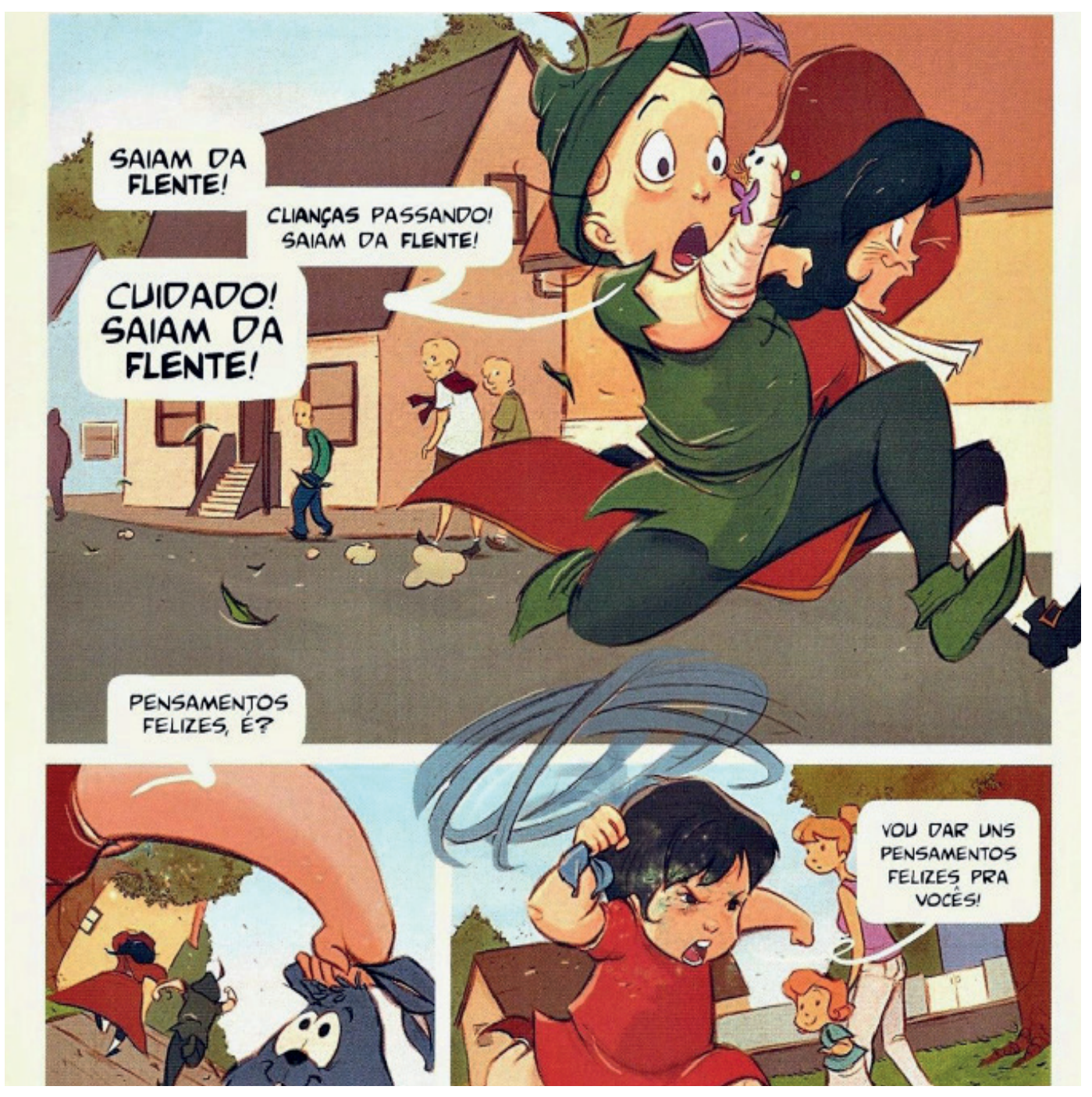

Fonte: Revista“Laços”(CAFAGGI, V.; CAFAGGI, L., p. 11), 2013.

$\mathrm{Na}$ Imagem 2, percebemos que Cebolinha e Cascão (primeiro quadro) estão exaltados, pela expressão de suas faces, olhos arregalados e bocas abertas, notamos que as personagens estão eufóricas. Há também a possibilidade de indicação de alterações de volume na fala, já que o texto verbal se apresenta em letras maiores em um dos balões da cena. $O$ fato da imagem denotar, também, que as personagens estão correndo, pode acrescentar informações para a leitura das falas nos balões, pois é possível que as letras maiores evidenciem também a proximidade dos meninos; como eles estão correndo, a tendência é que suas falas se distanciem, por isso a redução no tamanho da letra. Essa 
composição incita uma leitura mais rápida, é como a expressão "de modo rápido", por exemplo, anunciasse a cena. Vejamos um possível exemplo de como seria se essa cena tivesse sido descrita, sem o suporte da linguagem não verbal:

Cebolinha e Cascão correm apavorados de Mônica que, enfurecida, quer bater nos jovens com seu coelho. Cebolinha, eufórico, correndo, disse de modo rápido aos que atravessam seu caminho e de seu amigo Cascão:

- Saiam da flente! Clianças passando! Saiam da flente! CUIDADO! SAIAM DA FLENTE!

(Exemplo criado pelas autoras)

A expressão "de modo rápido" é usada no exemplo acima como um MPL, por denotar um determinado comportamento prosódico possível nesse caso. O modo como é dito por Cebolinha tem uma característica específica, que deve ser respeitado na leitura. Dessa forma, indica-se que a leitura seja feita de forma eufórica e rápida. Portanto, é evidente a influência da Prosódia Visual Imagética no comportamento do leitor dos quadrinhos. 
Imagem 3:

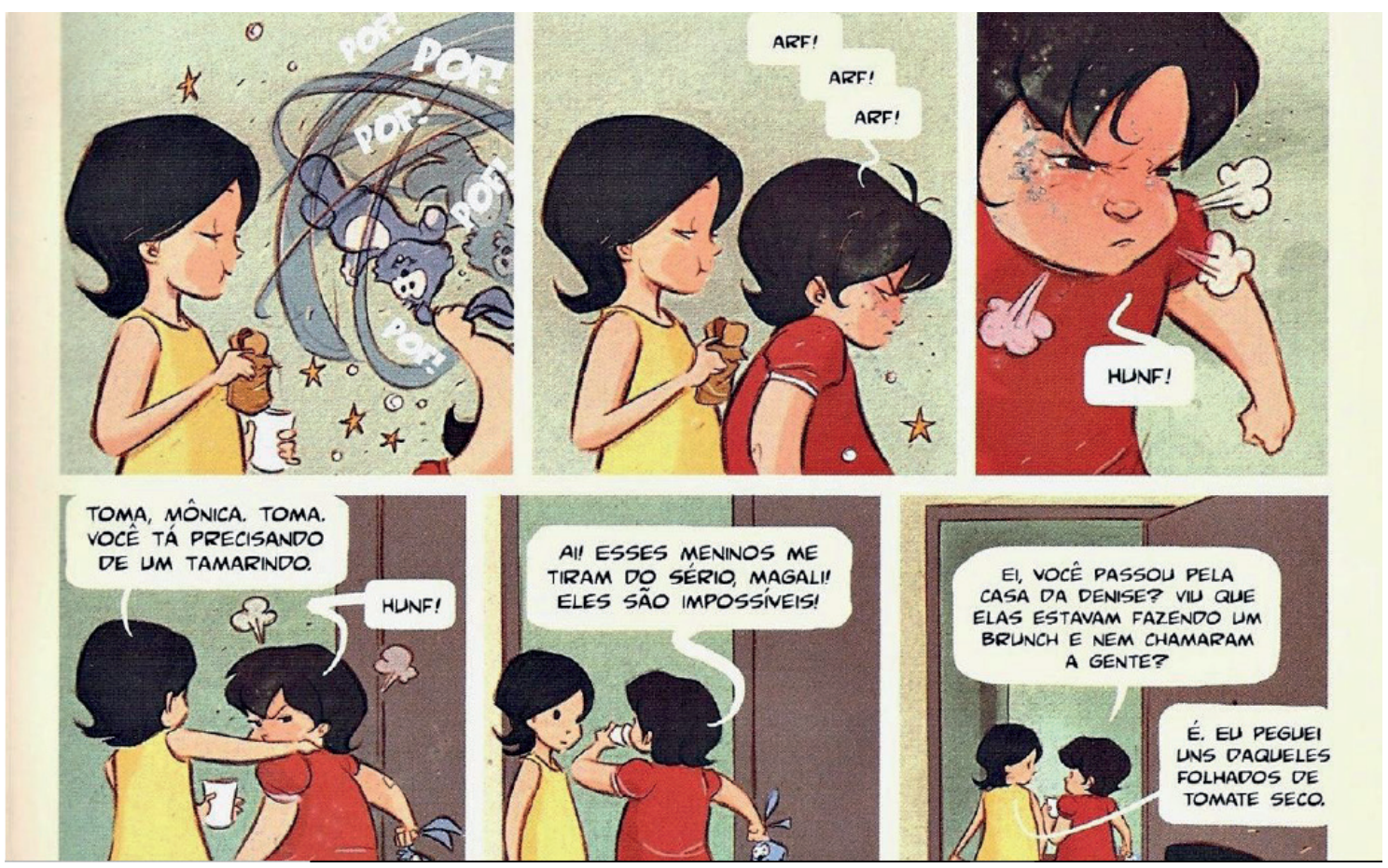

Fonte: Revista "Laços” (CAFAGGI, V.; CAFAGGI, L., p. 17), 2013.

É possível interpretar um sentimento por meio da PVI. Por exemplo, a personagem Mônica, nos quadrinhos da Imagem 3, é desenhada com o rosto enfurecido, olhos "apertados", sobrancelhas levantadas, boquinha fechada e a face com uma coloração vermelha. Diante dos estudos de Ekman e Friesen (1978) vimos que é possível se identificar emoções por meio das características da face, logo, a representação gráfica dessas emoções também carregam significações.

Os desenhos da fumaça (no segundo quadro) representam a raiva da personagem, complementando a leitura de que a menina está enfurecida. A face raivosa de Mônica fica mais evidente ao compararmos com a de sua amiga Magali (no primeiro quadro), que se encontra com uma expressão de plenitude, tranquila, comendo calmamente seu lanche. Enquanto isso, a brava Mônica "solta fogo pelas ventas", com raiva dos meninos peraltas (Cebolinha e Cascão). Esses elementos das imagens indicam uma forma de se ler as onomatopeias colocadas como falas de Mônica. É nítido que a linguagem visual contribui para a interpretação da cena e atribui significados que não precisam ser escritos para serem percebidos. 
Portanto, a prosódia visual de "Laços"não apenas contribui, mas também se faz essência para a leitura do todo na narrativa. Sendo importante levar em consideração cada recurso utilizado na escrita, para assim guiar melhor o comportamento prosódico do leitor.

\section{CONSIDERAÇÕES FINAIS}

Considerando que o objetivo deste trabalho foi analisar a Prosódia Visual Imagética, na HQ “Laços”, e diante do resultado da análise feita, foi possível perceber que as imagens desenhadas que constituem a linguagem não verbal podem ser consideradas como MPVI em "Laços". Assim os movimentos representados por meios dos contornos que evidenciam gestos e expressões faciais das personagens, funcionam como estratégia de marcação prosódica para uma leitura mais completa da narrativa. Portanto, é possível dizer que na prosódia visual observamos marcadores de natureza diferente dos MPL, bem como que a prosódia nesta HQ se manifesta a partir de MPG, na linguagem verbal, e MPVI, no caso da linguagem não verbal.

Sendo assim, observamos que os MPL tradicionalmente presentes em outros gêneros narrativos, como romances (CAGLIARI, 2002) não aparecem em "Laços". Nossa hipótese é de que isso ocorra, pois a prosódia pode ter manifestações diferentes: i) na fala, por exemplo, ela se manifesta a partir das variações melódicas e da presença de gestos; ii) na escrita, por meio de marcadores gráficos e lexicais; iii) já nas HQs, há a presença dos MPVI, pois, diferentemente das narrativas tradicionais, em uma novela gráfica as imagens participam da narração da história de modo que as GN podem ser construídas sem a presença de um narrador. Logo, esse resultado reforça a importância comunicativa da prosódia em suas diversas manifestações. 


\section{REFERÊNCIAS:}

BRANDÃO, D. A linguagem dos quadrinhos. Projeto HQ. Fascículo no 001. Ceará 2. Fortaleza, 2017.

CAGLIARI, L. C. A escrita do barulho. In: Estudos Linguísticos - Anais de seminários do GEL. v. 22. São Paulo, Instituição Moura Lacerda, 1993. p. 615-622.

CAGLIARI, L. C.. Marcadores prosódicos na escrita. In: Seminário do grupo de estudos lingüísticos, 18, 1989, Lorena. Anais do XVIII Seminário do Gel. Lorena: Grupo de Estudos Lingüísticos de São Paulo, 1989. p. 195-203.

CAGLIARI, L. C. A estrutura prosódica do romance A Moreninha. Oxford: Estágio PósDoutoral, 2002. (Relatório).

CAGLIARI, L. C. Breve História da Pontuação. In: CONGRESSO BRASILEIRO DE LINGÜÍSTICA APLICADA, 4, 1995, Campinas. Anais. Campinas: Unicamp, 1995. p.177-183.

CAGNIN, A. L. Os quadrinhos. São Paulo: Ática, 1975.

CARPES, D. R. P.; SEARA, I. C. Estratégias metodológicas para investigar a prosódia do fogo no português brasileiro. Revista do Gel, v.14, n.2, 2017.

CATACH, N. La ponctuation estles sustèmes d'ecriture: dedans ou dehors? In: DEFAYS, J-M. ROSIER, L. TILKIN, F., (Orgs.). À qui appartient la punctuation?Paris: Duculot, 1998. cap. 2, p. 31-46.

EGUTI, C. A. A representatividade da oralidade nas histórias em quadrinhos. 198f. Dissertação (Mestrado em Filologia e Língua Portuguesa) - Faculdade de Filosofia e Língua Portuguesa, Universidade de São Paulo, São Paulo, 2001.

EISNER, W. Um Contrato com Deus e outras histórias de cortiço. São Paulo: Devir, 2009.

EKMAN, P. Basic emotions. In: DALGLEISH, T.; POWER, T.(eds.) The Handbook of Cognition and Emotion. Sussex, UK: John Wiley e Sons, 1999.

EKMAN, P. Facial expressions of emotion: new findings, new questions. Psychological Science, 1992.

EKMAN, P. Pan-cultural Elements in Facial Display of Emotion. Science, 1969.

EKMAN, P. Universals and cultural differences in facial expressions of emotion. In: COLE, J. K.(ed.) Nebraska symposium on motivation. Lincoln: University of Nebraska Press., 1972.

EKMAN, P.; FRIESEN, W. V. A technique for the Measurement of Facial Movement. Consulting Psychologists Press: Palo Alto, 1978.

MAINGUENEAU, D. Discurso literário. Trad. Adail Sobral. São Paulo: Contexto, 2006.

MARCUSCHI, L. A. Oralidade e escrita. Signótica. Goiás, v. 9, p. 119- 145, 1997. 
MUNHALL, K. G. et al. Visual prosody and speech intelligibility: head movement improves auditory speech perception. Psychological Science, v. 15, n. 2, p. 133-137, 2004.

PACHECO, V. Investigação fonético-acústico e experimental dos sinais de pontuação enquanto marcadores prosódicos. Dissertação (mestrado em Lingüística) 132 f. Instituto de Estudos da Linguagem, Unicamp, Campinas: 2003.

PACHECO, V. O efeito dos estímulos auditivo e visual na percepção dos marcadores prosódicos lexicais e gráficos usados na escrita do português brasileiro. 2006. 349p. Tese (Doutorado em Linguística) - Instituto de Estudos da Linguagem, Universidade Estadual de Campinas, 2006.

PACHECO, V. O efeito dos estímulos auditivo e visual na percepção dos marcadores prosódicos usados na escrita do PB. Sínteses, v. 12, p.235-245, 2007.

PACHECO, V.Percepção de ênfase e atenuação: o papel dos movimentos faciais e corporais. Anais do III Colóquio Brasileiro de Prosódia da Fala. 2011. Disponível em: <http://www. periodicos.letras.ufmg.br/index.php/anais_coloquio/article/view/1263/1377>. Acesso em: 29 jun. 2016.

PASSARELLI, L. G. Os quadrinhos na educação lingüística: história, teoria e prática. In: BASTOS, N. B. (org.). Língua Portuguesa em calidoscópio. São Paulo: EDUC, 2004. p. 47-59.

RAMOS, P. Histórias em quadrinhos: gênero ou hipergênero? Estudos Linguísticos XXXVIII. 2009. p. 355-367.

RAMOS, P. A leitura dos quadrinhos. São Paulo: Contexto, 2012.

RAMOS, P. Histórias em quadrinhos: um novo objeto de estudos. Estudos Linguísticos XXXV, 2006.

RAMOS, P. Piadas e tiras em quadrinhos: a oralidade presente nos textos de humor. Estudos Linguísticos XXXI, 2005.

RAMOS, P. Tiras cômicas e piadas: duas leituras, um efeito de humor. 2007. 424 f. Tese (Doutorado em Letras. área de concentração: Filologia e Língua Portuguesa) Faculdade de Filosofia e Língua Portuguesa, Universidade de São Paulo, SP.

SANTOS, R. E. Revista em quadrinhos, álbuns e Graphic novels em sala de aula. Fortaleza: Fundação Demócrito Rocha, fascículo 9, 2018.

SILVA, A. V. Os marcadores prosódicos na história em quadrinhos Laços. Dissertação (Mestrado Acadêmico em Letras) - Fundação Universidade Federal de Rondônia, 2019.

VERGUEIRO, W. A linguagem dos quadrinhos. São Paulo: Criativa, 2015.

ZIMBRES, F. Quadrinhos em sala de aula. Projeto HQ. Fascículo no 002. Ceará 2. Fortaleza, 2017. 